\title{
The Merits of Mate Selection with a Limited Maximum Inbreeding Coefficient for Progeny Animals
}

\author{
Tetsuro Nomura and Katsuei YonezAwA \\ Faculty of Engineering, Kyoto Sangyo University, \\ Kita-ku, Kyoto-shi 603
}

(Received October 21, 1993)

Key words : mate selection, restriction on inbreeding, genetic gain, computer simulation

It is well known that inbreeding causes depressive effects on fitness related characteristics such as reproductive performance, viability and fecundity ${ }^{3}$. Inbreeding in a selection programme, therefore, should be kept as low as possible. In order to avoid promoting inbreeding, however, selection intensity should not be high, and consequently, response to selection should be relatively small. Inbreeding is of special importance in advanced selection schemes such as combined selection methods and the BLUP method, where fewer families with high performance provide larger contributions to progeny generations than in other ordinary individual selection schemes ${ }^{2,6,7,9)}$.

In order to cope with this problem, ToRo and PÉREZ-ENCISO ${ }^{10)}$ proposed a selection scheme named mate selection. In this selection scheme, mating combinations are arranged in such a way that genetic gain by selection should be maximized under the condition that an increase in the average inbreeding coefficient for progeny animals should be smaller than a critical value imposed. Using a Monte
Carlo simulation, they showed that by mate selection, inbreeding could be suppressed to an acceptably low level without substantial reduction in genetic advances compared to that achieved by ordinary selection with random mating.

Inbreeding of all individual animals is important as well as average inbreeding; a population with a relatively low value of average inbreeding may contain a number of highly inbred animals, which may cause reduced population size and limited response to selection in later stage of selection. In this paper, the efficiency of mate selection will be investigated on the strength of the Monte Carlo simulation, taking into account the degree of inbreeding of all individual animals.

\section{Models of Simulation}

Procedures of mate selection can be modelled by defining a matrix $\mathrm{X}=\left[\mathrm{x}_{\mathrm{ij}}\right]\left(\mathrm{i}=1,2, \ldots, \mathrm{N}_{\mathrm{M}} ; \mathrm{j}=\right.$ $\left.1,2, \ldots N_{F}\right)$, where element $x_{i j}$ represents a decision variable which takes unity or zero depending on whether the $i$-th male and $j$-th female are

後代個体の近交䋆数に最大許容值を設けた mate selection の有效性汇ついて：野村哲郎．米澤勝衛（京都産業大 学工学部, 京都市北区 603) 


\section{NOMURA and YoNEZAWA}

mated or not. $N_{M}$ and $N_{F}$ are the numbers of candidate sires and dams, respectively. In the mate selection of Toro and PÉrez-ENCISO ${ }^{10}$, the matrix $\mathrm{X}$ was determined so as to maximize the genetic progress $\sum \sum_{j} \mathbf{x}_{i j}\left(\hat{a}_{i}+\hat{a}_{j}\right) / 2\left(\hat{a}_{i}\right.$ and $\hat{a}_{j}$ are the estimates of breeding values of the $i-$ th male and $\mathbf{j}$-th female, respectively) with subject to the following restrictions :

(i) $x_{i j}=0$ or 1 (for all combinations of $i$ and $j$ )

(ii) $\sum_{i} \sum_{j} x_{i j}=M$

(iii) $\sum_{i} x_{i j} \leq S$ (for all values of $j$ )

(iv) $\sum_{\mathrm{j}} \mathrm{x}_{\mathrm{ij}} \leq \mathrm{D}$ (for all values of $\mathrm{i}$ )

(v) $\sum_{i} \sum_{j} x_{i j} f_{i j} / M \leq F+F I$,

where $M$ is the total number of mates, and $S$ and $\mathrm{D}$ are the maximum numbers of sires per dam and of dams per sire, respectively. Symbols $f_{i j}, F$ and $F I$ respectively indicate the coancestry coefficient between the $\mathrm{i}$-th male and the $j$-th female, the average inbreeding coefficient in the previous generation, and the maximum permitted increase rate of average inbreeding. To keep the inbreeding coefficients of all individual animals below FMAX, a restriction,

(vi) $\mathrm{x}_{\mathrm{ij}} \mathrm{f}_{\mathrm{ij}}<$ FMAX (for all combinations of $\mathrm{i}$ and $\mathrm{j}$ )

has been added in this paper. The integer programming technique ${ }^{4)}$ provides a general solution for the matrix $\mathrm{X}$.

The trait subject to selection was assumed to be controlled by 60 independent loci with 2 alleles each ( + and - ). Additive gene action was assumed, with genotypic values for the three genotypes,+++- and -- being 1,0 , and -1 at each locus. The initial frequency of + allele was set to be 0.5 , meaning that the initial additive genetic variance was 30 under the Hardy-Weinberg segregation ratio. The phenotypic value of an individual was given by adding a normal random number with mean 0 and variance 45 to its genotypic value, which defines initial heritability to be 0.4 . Selection was carried out based on the phe- notypic value.

To create the initial population ( 32 animals of each sex), 4 progenies of each sex were generated from each of eight pairs of unrelated founder animals. In subsequent generations, eight pairs of mates, using different sires and dams in different pairs, i.e., a case of $M=8$ and $\mathrm{S}=\mathrm{D}=1$, were made via mate selection, with each pair leaving 4 progenies (a total of $4 \times 8=$ 32 progenies) of each sex. Prior to the mate selection in each generation, a preliminary selection was made to select the best 16 male and 16 female candidates, and then, the values of $\mathrm{N}_{M}$ and $\mathrm{N}_{F}$ were set at 16 . This preliminary selection not only saves computation time, but also creates the advantage that a higher selection differential will be attained by eliminating individuals showing below average performance ${ }^{8)}$.

Three types of mate selection, i.e., mate selection of TORO and PÉREZ-ENCISO ${ }^{10)}$ (symbolized by MS1), mate selection with additional restriction (vi) (MS2), and mate selection with restriction (vi) excluding (v) (MS 3), were compared. Four values of FI, i.e., 0.03, 0.04, 0.05 and 0.06, were chosen according to TORO and PÉREzENCISO $^{10)}$ where $\mathrm{FI}=0.05$ was calculated with the same scale and scheme of selection as studied in this paper. As for FMAX, two values 0.15 and 0.20 were chosen, both of which were small enough to avoid full-sib mating. In some replicated runs of the simulation, mating combinations that satisfied the critical value of FI became inpracticable in later generations. In such cases, the restriction on FI was relaxed to FI+0.01. Solutions for mate selections were obtained using a computer programme for integer programming (MIP) provided by IBARAKI and Fukushima ${ }^{4)}$. As a case with no restrictions on inbreeding, a selection scheme (RM), in which the best 8 of each sex were selected and mated at random, was additionally computed. Six generations of selection were performed for each of the four selection schemes with 50 replicated runs. 


\section{Nomura and Yonezawa}

RM. The reduction in genetic gain, on the other hand, was only $4 \%$.

Efficiency of mate selection depends critically on the intensity of restrictions on the progress of inbreeding. In order to find the optimal restriction, the depressive effects of inbreeding need to be quantitatively evaluated. The inbreeding depression on individual traits may somehow be evaluated ${ }^{1)}$, but the overall effect of inbreeding on the advancement of selection is difficult to measure. However, experienced breeders have some idea on a tolerable degree of inbreeding. In Japanese Black Cattle, for example, matings among individuals more closely related than half-sibs have been empirically known to cause seriously reduced viability of progenies ${ }^{12)}$. To avoid such close matings, a restriction of FMAX $=0.125$ could be used as a standard. Breeders mostly have little concern with average inbreeding.

Mate selection with a fixed value of FMAX becomes impracticable in later generations since coancestry among animals gets larger as average inbreeding progresses. The restriction on FMAX should be relaxed in this case. In practice, when inbreeding depression is not serious after several cycles of selection, selection thereafter may be carried out by paying little attention to the progress of inbreeding.

A reproductive technique, the so-called multiple ovulation and embryo transfer method (MOET), makes it possible to produce many progenies from a single female. This technique is expected to make a great contribution toward the breeding of animals with low reproductive abilities ${ }^{5,13)}$. Selection using this technique, however, may cause high inbreeding due to high contributions of maternal half-sibs and full-sibs. To cancel this negative aspect of MOET, some modified methods, e.g., avoiding mating among full-sibs ${ }^{19)}$ and selecting only one male per full-sib family ${ }^{5)}$, have been proposed. Recently, Toro et al. ${ }^{11)}$ studied the application of mate selection in dairy cattle breeding using MOET, leading to the conclu- sion that mate selection with a restricted average increase rate of inbreeding is useful for reducing inbreeding, without causing any serious loss in genetic gain. A restriction on the inbreeding of all individual animals will make a further reduction in inbreeding, while it may reduce genetic gain because of limitations of mating combinations in future generations. The mate selection scheme that best fits with MOET remains to be investigated.

\section{References}

1) BRINKS, J.S. and B.W. KNAPP, Effects of inbreeding on performance traits of beef cattle in the Western region. Tech. Bull., 123. Colorado State Univ. Exper. Sta. Cololado. 1975.

2) BuRrows, P.M., Inbreeding under selection from unrelated families. Biometrics, $40: 357-$ 366. 1984.

3) FALCONER, D.S., Introduction to quantitative genetics. 3rd ed. 248-263. Longman Sci. \& Tech. London. 1989.

4) IBARAKI, T. and M. FuKushima, FORTRAN77 : Programming for optimization. 395-452. Iwanami Shoten. Tokyo. (in Japanese) 1991.

5) NichOLAS, F.W. and C. SMITH, Increased rates of genetic change in dairy cattle by embryo transfer and splitting. Anim. Prod., $36: 341$ 353. 1983.

6) Quinton, M., C. SMith and M.E. Goddard, Comparison of selection methods at the same level inbreeding. J. Anim. Sci., 70 : 1060-1067. 1992.

7) RoBERTSON, A., Inbreeding in artificial selection programmes. Genet. Res., 2 : 189-194. 1961.

8) SMITH, C., Optimum selection procedures in animal breeding. Anim. Prod., $11: 433-442$. 1969.

9) Toro, M.A., L. Silió, J. Rodriganez and M.T. DOBAO, Inbreeding and family index selection for prolificacy in pigs. Anim. Prod., 46 : 79-85. 1988.

10) ToRo, M. and M. PÉREz-ENCISO, Optimization of selection response under restricted inbreeding. Genet. Sel. Evol., 22 : 93-107. 1990.

11) TORo, M., L. Silió and M. PÉrez-Enciso, A note on the use of mate selection in closed MOET breeding schemes. Anim. Prod., $53: 403-406$. 1991.

12) UCHIDA, H. and T. Y AMAGISHI, The influences of inbreeding on the market performance of calves, body measurements and fattening per- 


\section{Mate Selection with Restiction on Inbreeding}

formance in Japanese Black Cattle. (in Japanese) Anim. Sci. Technol. (Jpn.), 64 : 819-825. 1993.

13) Woolliams, J.A., Modifications to MOET nu- cleus breeding schemes to improve rates of genetic progress and decrease rates of inbreeding in dairy cattle. Anim. Prod., $49: 1-14.1989$. 